\title{
Birth weight and the insulin resistance syndrome: association of low birth weight with truncal obesity and raised plasminogen activator inhibitor-1 but not with abdominal obesity or plasma lipid disturbances
}

\author{
L. Byberg ${ }^{1}$, P.M. McKeigue ${ }^{2}$, B. Zethelius ${ }^{1}$, H. O. Lithell ${ }^{1}$ \\ ${ }^{1}$ Department of Public Health and Caring Sciences/Geriatrics Unit, Uppsala University, Sweden \\ ${ }^{2}$ Department of Epidemiology and Population Health, London School of Hygiene and Tropical Medicine, UK
}

\begin{abstract}
Aims/hypothesis. To distinguish the physiological disturbances related to birth weight from the cluster of disturbances called the insulin resistance syndrome. Methods. Men participating in a population-based study in Uppsala, Sweden, with recordings of birth weight, were metabolically characterised at age 50 $(n=1268)$ and re-investigated at age $70(n=734)$. Blood pressure, BMI, glucose and insulin concentrations are associated with birth weight in this cohort. Results. Birth weight was inversely associated $(p<0.03)$ with subscapular:triceps skinfold ratio (truncal fat), plasminogen activator inhibitor-1 (PAI1) activity, specific insulin and proinsulin-like molecules when adjusted for BMI. Birth weight was not related $(p>0.10)$ with waist circumference, serum triglycerides or HDL cholesterol. The insulin resistance syndrome was defined as the combination of hypertension, insulin resistance and dyslipidaemia. The prevalence of this syndrome at age 50 and 70 was in-
\end{abstract}

versely related to birth weight with odds ratio 0.66 and 0.71 , respectively, per $\mathrm{kg}$ increase in birth weight. When the syndrome was defined to include truncal obesity or raised plasminogen activator inhibitor-1 instead of dyslipidaemia, the corresponding odds ratios were 0.51 and 0.66 , respectively.

Conclusions/interpretation. Low birth weight predicts high blood pressure, insulin resistance, truncal obesity and high plasminogen activator inhibitor-1 activity but not the abdominal obesity or dyslipidaemia present in the insulin resistance syndrome. The cluster of disturbances associated with low birth weight is a subset of the disturbances that are clustered in the general population as the insulin resistance syndrome. This subset of physiological disturbances is possibly linked by a specific pathway. [Diabetologia (2000) 43: 54-60]

Keywords Insulin resistance, birth weight, hyperlipidaemia, plasminogen activator inhibitor-1, waist:hip ratio, proinsulin.
Small size at birth predicts physiological disturbances in adult life, such as raised blood pressure [1-3], Type II (non-insulin-dependent) diabetes mellitus [4-6], impaired glucose tolerance $[4,7]$ and insulin resistance $[6,8,9]$. All these conditions are associated with an increased risk of and mortality from cardio-

Received: 14 May 1999 and in revised form: 15 July 1999

Corresponding author: L. Byberg, Geriatrics Unit, Department of Public Health and Caring Sciences, P. O. Box 609, SE75125 Uppsala, Sweden

Abbreviations: PAI-1: Plasminogen activator inhibitor-1, OR: odds ratio. vascular disease [10-12]. The cluster of risk factors for cardiovascular disease that are associated with insulin resistance, the insulin resistance syndrome, includes hypertension, impaired glucose tolerance, insulin resistance, lipid disturbances such as high serum triglyceride and low HDL cholesterol concentrations, and impaired fibrinolytic activity, mediated by a high plasminogen activator inhibitor-1 (PAI-1) activity [13]. Low birth weight predicts most of these disturbances and has been associated with the insulin resistance syndrome itself $[14,15]$. After very high odds ratios for people with low birth weight to develop this syndrome had been shown, it was suggested that the insulin resistance syndrome should be renamed the 
'small baby syndrome' [14]. Most studies have, however, failed to show an association between low birth weight and the high serum triglyceride and low HDL cholesterol concentrations seen in the insulin resistance syndrome [6,15-18].

The aim of this study was to distinguish the physiological disturbances related to birth weight from the insulin resistance syndrome, in a population-based study of men investigated at ages 50 and 70 years.

\section{Subjects and methods}

The Uppsala Longitudinal Study of Adult Men (ULSAM) has been described previously $[2,6,19,20]$. All men born between 1920 and 1924 and living in Uppsala, Sweden $(n=2841)$, were invited to a health investigation which took place from 1970 to 1973 (2322 men participated). In 1991, 1221 of the men were re-examined. During the 20 intervening years, 422 men had died and 219 had moved out of the Uppsala region. Of the 1681 men invited, 460 did not participate in the re-examination. The study was approved by the local ethics committee and all participants gave their informed consent. All investigations were done after an overnight fast.

We were able to trace the birth records of 1333 participants [2]. Of those, 615 were born in the Uppsala Academic Hospital where the records, in addition to birth weight, also contained information on gestational age. The birth weights were grouped into four categories, where the cut-offs were chosen to take account of the frequent rounding to the nearest $0.5 \mathrm{~kg}$ in the original birth records. The groups were thus less than $3.25,3.25$ or more to less than $3.75,3.75$ or more to less than 4.25 and $4.25 \mathrm{~kg}$ or more [2].

Investigations at age 50 included height, weight, skinfold measurements, supine blood pressures, intravenous glucose tolerance test and blood lipids including serum and HDL triglycerides and cholesterol [2, 6, 19]. Skinfolds were measured to the nearest $0.2 \mathrm{~mm}$ on the triceps, subscapular and to the right of the umbilicus using a Harpenden calliper [21]. The ratio of subscapular to triceps skinfolds was used as an index of truncal fat [22].

At age 70, an oral glucose tolerance test and a euglycaemic hyperinsulinaemic clamp were done, as were measurements of height, weight, waist and hip circumferences, and supine blood pressures [20]. Serum triglycerides and HDL cholesterol concentrations were assayed by enzymatic techniques (Instrumentation Laboratories, Lexington, Mass., USA). Plasminogen activator inhibitor-1 activity was measured with an indirect enzymatic assay (Spectrolyse/pL PAI, Biopool AB, Umeå, Sweden).

The fasting concentrations of plasma specific insulin, intact and 32, 33 split proinsulin were determined by two-site immunometric assays [23] at both ages. The samples were stored in $-70{ }^{\circ} \mathrm{C}$ until analysis (in 1994-1998 and 1998 for samples drawn at ages 50 and 70 years, respectively).

Information on smoking was collected by interview. At age $50,52.2 \%(n=662)$ were regular smokers. The corresponding proportion at age 70 was $21.9 \%(n=155)$. Socio-economic class at birth was based on the profession of the father or of the mother if she was single as stated in the birth records. Socio-economic variables (marital status, type of work, educational level) at ages 50 and 70 were collected from the Swedish censuses of 1970 and 1990, respectively.

Type II diabetes mellitus and impaired glucose tolerance were defined according to the World Health Organisation
(WHO) criteria from 1985 [24], based on the results from the oral glucose tolerance test at age 70 . At age 50 , the criteria for Type II diabetes were fasting blood glucose $6.7 \mathrm{mmol} / \mathrm{l}$ or more and K-value (from the intravenous glucose tolerance test) 0.9 or less or anti-diabetic therapy or both. To minimise the inclusion of Type I (insulin-dependent) diabetes mellitus in this definition, men on insulin treatment were not included.

The prevalence of hypertension was defined as supine systolic blood pressure higher than $140 \mathrm{mmHg}$ or diastolic blood pressure higher than $90 \mathrm{mmHg}$ or ongoing anti-hypertensive treatment or a combination of these.

There is no agreed definition of the insulin resistance syndrome, although a working definition has been suggested [25], from which our definition does not differ very much. We defined it as the combination of hypertension, glucose intolerance or insulin resistance and dyslipidaemia (see below), the three major constituents of the syndrome. Glucose intolerance and insulin resistance often coexist but it is possible to be insulin resistant without being glucose intolerant, and vice versa. Glucose intolerance is characterised by an impaired ability of the body tissues to efficiently reduce increased glucose concentrations in the blood. Type II diabetes, impaired glucose tolerance and high fasting glucose concentrations are measures of glucose intolerance. When the body tissues' response to insulin, the insulin sensitivity, is reduced, it is called insulin resistance. Measures of insulin resistance are low insulin sensitivity index, here determined by clamp, and high fasting insulin concentrations, often used as a proxy when other measures of insulin sensitivity are not available.

The definition of the cluster of factors associated with birth weight was based on those variables associated with birth weight in this cohort (Tables 1 and 2 and [2, 3, 6, 9]). We used different definitions of the syndromes for ages 50 and 70 , because of the different investigations carried out. The cut-off values were based on the highest or lowest tertile of a variable (median for subscapular:triceps skinfold ratio) at each age. The two outcomes were defined by A-D below, at age 50 and 70 , respectively. The insulin resistance syndrome was defined as $\mathrm{A}$ and $\mathrm{B}$ and $\mathrm{C}$ and the cluster of birth weight-associated factors as $\mathrm{A}$ and $\mathrm{B}$ and $\mathrm{D}$.

At age 50: A. BP-lowering treatment or high supine systolic $\mathrm{BP}(\geq 140 \mathrm{mmHg})$, B. high fasting plasma insulin $(\geq 13.8 \mathrm{mU} /$ 1) or high fasting blood glucose $(\geq 5.05 \mathrm{mmol} / \mathrm{l})$ or Type II diabetes, C. low HDL cholesterol $(<1.0 \mathrm{mmol} / \mathrm{l})$ or high serum triglycerides $(\geq 2.20 \mathrm{mmol} / \mathrm{l})$, D. high subscapular/triceps skinfold ratio $(>1.553)$.

At age 70: A. BP-lowering treatment or high supine systolic BP $(\geq 154 \mathrm{mmHg})$, B. low insulin sensitivity index $(\mathrm{M} / \mathrm{I}$ from clamp $\left.<3.65 \mathrm{mg} \cdot \mathrm{min}^{-1} \cdot \mathrm{kg}^{-1} \cdot(\mathrm{mU} / \mathrm{l})^{-1} \cdot 100\right)$ or impaired glucose tolerance or Type II diabetes, C. low HDL cholesterol $(<1.1 \mathrm{mmol} / \mathrm{l})$ or high serum triglycerides $(\geq 1.57 \mathrm{mmol} / \mathrm{l})$ or lipid-lowering medication, D. high PAI-1 activity ( $>19.2 \mathrm{U} / \mathrm{ml})$.

The insulin resistance syndrome was defined in 2202 of the 2322 50-year-old men, of whom 1268 also had recordings of birth weight. At age 70 it was coded as present/absent in 1218 (of 1221) men, of whom 734 also had birth weight recorded. There were no differences in anthropometric measurements, diabetes prevalence, fasting lipid, glucose or immunoreactive insulin concentrations between the men included and those not. At age 50, the systolic and diastolic blood pressures and the prevalence of hypertension were lower among the men included when compared with those not included $(p<0.05)$. There was no such difference at age 70 . The cluster of factors associated with birth weight was defined in 1165 and 678 men aged 50 and 70 , respectively.

In the group of men born in Uppsala Academic Hospital the effect of gestational age on the relation of birth weight 
Table 1. Characteristics at age 50, presented as means \pm SD $(n)$ and their association with birth weight

\begin{tabular}{|c|c|c|c|c|c|c|}
\hline & \multicolumn{6}{|c|}{ Birth weight group (kg) } \\
\hline & $<3.25$ & -3.75 & -4.25 & $\geq 4.25$ & $p$ & $p^{\mathrm{a}}$ \\
\hline Umbilical skinfold (mm) & $20.4 \pm 10.1(163)$ & $20.4 \pm 9.8(319)$ & $20.0 \pm 9.6(208)$ & $20.5 \pm 10.0(70)$ & 0.904 & 0.029 \\
\hline Subscapular skinfold (mm) & $17.4 \pm 6.1(163)$ & $16.6 \pm 5.8(319)$ & $16.7 \pm 6.1(208)$ & $16.6 \pm 5.6(70)$ & 0.462 & 0.001 \\
\hline Subscapular:triceps skinfold ratio & $1.78 \pm 0.54(163)$ & $1.60 \pm 0.48(319)$ & $1.57 \pm 0.52(208)$ & $1.54 \pm 0.43(70)$ & $<0.001$ & $<0.001$ \\
\hline Specific insulin $(\mathrm{pmol} / \mathrm{l})$ & $51 \pm 44(214)$ & $51 \pm 37(374)$ & $50 \pm 38(296)$ & $52 \pm 45(83)$ & 0.518 & 0.380 \\
\hline Proinsulin (pmol/l) & $2.9 \pm 3.5(215)$ & $2.8 \pm 2.6(376)$ & $3.0 \pm 4.1(295)$ & $2.9 \pm 3.1(83)$ & 0.430 & 0.652 \\
\hline
\end{tabular}

$p$ values were adjusted for age and $p^{\text {a }}$ for age and BMI.

The associations of birth weight with BMI, insulin resistance, fasting plasma immunoreactive insulin and serum lipid concentrations at age 50 have been investigated previously [6].

Table 2. Characteristics at age 70, presented as means \pm SD $(n)$ and their association with birth weight

\begin{tabular}{|c|c|c|c|c|c|c|}
\hline & \multicolumn{6}{|c|}{ Birth weight group (kg) } \\
\hline & $<3.25$ & -3.75 & -4.25 & $\geq 4.25$ & $p$ & $p^{\mathrm{a}}$ \\
\hline $\mathrm{BMI}\left(\mathrm{kg} / \mathrm{m}^{2}\right)$ & $25.9 \pm 3.3(174)$ & $26.4 \pm 3.2(275)$ & $26.6 \pm 3.7(217)$ & $26.8 \pm 3.5(68)$ & 0.007 & - \\
\hline Hip circumference $(\mathrm{cm})$ & $99.2 \pm 8.0(173)$ & $100.4 \pm 6.2(268)$ & $101.4 \pm 7.7(211)$ & $101.7 \pm 7.2(66)$ & $<0.001$ & 0.024 \\
\hline Waist: hip ratio & $0.94 \pm 0.06(173)$ & $0.94 \pm 0.05(268)$ & $0.94 \pm 0.05(211)$ & $0.94 \pm 0.05(66)$ & 0.856 & 0.027 \\
\hline Specific insulin (pmol/l) & $54 \pm 40(169)$ & $55 \pm 66(261)$ & $50 \pm 43(209)$ & $49 \pm 30(67)$ & 0.440 & 0.010 \\
\hline Proinsulin $(\mathrm{pmol} / \mathrm{l})$ & $8.6 \pm 7.4(167)$ & $8.9 \pm 7.1(259)$ & $7.9 \pm 7.2(207)$ & $8.9 \pm 16.5(66)$ & 0.106 & 0.001 \\
\hline HDL cholesterol $(\mathrm{mmol} / 1)^{\mathrm{b}}$ & $1.29 \pm 0.34(173)$ & $1.26 \pm 0.34(275)$ & $1.27 \pm 0.34(217)$ & $1.31 \pm 0.32(68)$ & 0.472 & 0.102 \\
\hline PAI-1 activity (U/ml) & $18.7 \pm 14.3(127)$ & $19.1 \pm 14.1(217)$ & $16.8 \pm 15.0(160)$ & $14.3 \pm 11.1(50)$ & 0.038 & $<0.001$ \\
\hline
\end{tabular}

$p$ values were adjusted for age and $p^{\text {a }}$ for age and BMI.

${ }^{\mathrm{b}} p$ values adjusted also for lipid lowering treatment.

with the metabolic variables and the two syndromes was investigated. Men with recordings of gestational age $(n=561$ and 326 at age 50 and 70 , respectively) were compared with men born at term (gestational age $\geq 38$ weeks; $n=496$ and 282 at age 50 and 70 , respectively), thus excluding pre-term births (gestational age $<38$ weeks). The validity of the classification of pre-term and term births in this cohort has been discussed previously [9].

Statistical analyses were done with the statistical software package Stata (Stata Corporation, College Station, Tex., USA). Skewed variables were transformed to reach normal distribution and the transformed variables were used in the analyses. Comparisons of included and not included men were done by Student's $t$-test or the chi squared test. Birth weight was used as a continuous variable in trend tests. Logistic regression was used to assess relations with the insulin resistance syndrome and the cluster of birth weight-associated factors and linear regression to assess the relations with metabolic variables. All relations were adjusted for age at the time of the investigation and, in a second model, for age and BMI at the time of the investigation. Variables standardised to $1 \mathrm{SD}$ were used for comparison of the effect of birth weight on variables. Odds ratios (OR) are presented with their $95 \%$ confidence intervals (CI). We regarded $p<0.05$ as significant.
The association of birth weight with insulin sensitivity at age 70 has been investigated previously [9].

\section{Results}

Of the 50-year-old men under study ( $n=1268), 1.2 \%$ had Type II diabetes and $26 \%$ were hypertensive. At age $70(n=734), 14 \%$ had Type II diabetes, $27 \%$ had glucose intolerance and $67 \%$ were hypertensive. The birth weight ranged from 1.40 to $5.40 \mathrm{~kg}$ (mean: 3.60 $\mathrm{kg}$ ). In the subgroup of men born in Uppsala Academic Hospital, the mean birth weight was $3.50 \mathrm{~kg}$ (range: $1.40-4.97 \mathrm{~kg}$ ) and the mean birth weights of those born pre-term and not pre-term were 3.14 and $3.55 \mathrm{~kg}$, respectively.

Variables investigated are presented in the four birth weight categories as arithmetic means and their standard deviations (SD), together with $p$ values from regression with birth weight with and without adjustment for BMI. (Tables 1 and 2).

At age 50, the triceps skinfold thickness was positively associated with birth weight but not independently of BMI. When adjusted for BMI, the skinfold thickness at the umbilicus and subscapula were inversely associated with birth weight, as was the subscapular:triceps skinfold ratio, here used as a measure of truncal fat. Of these, truncal fat was most strongly related to birth weight, with 0.30 standard deviation decrease per $\mathrm{kg}$ increase in birth weight $(-0.30 \mathrm{SD} /$ 
Table 3. The insulin resistance syndrome ${ }^{\mathrm{a}}$ at ages 50 and 70 years, respectively, and its relation to birth weight

\begin{tabular}{|c|c|c|c|c|c|c|}
\hline \multirow{2}{*}{$\begin{array}{l}\text { Birth weight } \\
\text { group (kg) }\end{array}$} & \multicolumn{3}{|l|}{50 years } & \multicolumn{3}{|l|}{70 years } \\
\hline & $\%(n)$ & OR (95\% CI) & $\begin{array}{l}\text { OR }(95 \% \mathrm{CI}) \\
\text { adjusted for BMI }\end{array}$ & $\%(n)$ & OR (95\% CI) & $\begin{array}{l}\text { OR }(95 \% \mathrm{CI}) \\
\text { adjusted for BMI }\end{array}$ \\
\hline$<3.25$ & $16.3(47)$ & 1.00 & 1.00 & $20.1(35)$ & 1.00 & 1.00 \\
\hline-4.25 & $9.6(36)$ & $0.54(0.34-0.86)$ & $0.49(0.29-0.75)$ & $18.0(39)$ & $0.87(0.52-1.45)$ & $0.79(0.43-1.27)$ \\
\hline$\geq 4.25$ & $13.4(15)$ & $0.79(0.42-1.48)$ & $0.55(0.28-1.08)$ & $10.3(7)$ & $0.46(0.19-1.08)$ & $0.32(0.13-0.80)$ \\
\hline Total $^{\mathrm{b}}$ & $12.5(159 / 1268)$ & $0.66(0.47-0.91)$ & $0.52(0.36-0.75)$ & $18.8(138 / 734)$ & $0.71(0.49-1.02)$ & $0.56(0.38-0.84)$ \\
\hline
\end{tabular}

a The insulin resistance syndrome was defined as the combination of hypertension, glucose intolerance or insulin resistance and dyslipidaemia.

$\mathrm{b}$ Total odds ratios are for $1 \mathrm{~kg}$ increase in birth weight.

$\mathrm{kg}$ ), when adjusted for BMI. The associations were still significant when pre-term births were excluded. The fasting concentrations of specific insulin and proinsulin at age 50 were not associated with birth weight but tended to decrease with increasing birth weight when adjusted for BMI, but the trends were not statistically significant.

Previously published results from this cohort showed inverse relations of birth weight with fasting concentrations of immunoreactive insulin and insulin resistance (at age 50) [6] and positive associations with BMI (at age 50) [6] and insulin sensitivity (at age 70) after adjusting for BMI [9]. Birth weight was also related to blood pressure at both ages $[2,3]$ but not with the concentrations of serum triglycerides or HDL cholesterol at age 50 [6].

Waist and hip circumferences and BMI measured at age 70 were positively associated with birth weight (Table 2). When adjusting for BMI, birth weight was inversely related to the waist:hip ratio $(-0.13 \mathrm{SD} / \mathrm{kg})$ and positively related to hip circumference $(+0.10$ $\mathrm{SD} / \mathrm{kg}$ ) but there was no relation between birth weight and waist circumference $(+0.008 \mathrm{SD} / \mathrm{kg})$. Plasminogen activator inhibitor-1 activity measured at age 70 was inversely related to birth weight (Table 2). A $1 \mathrm{~kg}$ increase in birth weight was associated with a 0.25 SD decrease in PAI-1 activity, when adjusted for BMI. This relation was of similar strength when only normoglycaemic men $(-0.22 \mathrm{SD} / \mathrm{kg}$, $p=0.004)$ and when men born at Uppsala Academic Hospital $(-0.27 \mathrm{SD} / \mathrm{kg}, p=0.016)$ were investigated. When only men born at term were included, the relation was somewhat stronger; 0.41 SD decrease in PAI-1 activity per kg increase in birth weight (adjusted for BMI).

The specific insulin, intact and split proinsulin concentrations at age 70 were inversely associated with birth weight only when adjusted for BMI ( -0.12 , -0.10 and $-0.13 \mathrm{SD} / \mathrm{kg}$ increase in birth weight, respectively). The associations with intact and 32, 33 split proinsulin concentrations were of similar strength and remained significant also when including only men with normal glucose tolerance $(p=0.013$ and 0.049 , respectively). Split proinsulin was related to birth weight also in the subgroup of men born at term $(-0.24 \mathrm{SD} / \mathrm{kg}$ decrease, adjusted for BMI).

The associations of serum triglycerides and HDL cholesterol, measured at age 70 , with birth weight were adjusted also for use of lipid lowering agents (Table 2). Serum triglyceride concentrations were not associated with birth weight. High density lipoprotein cholesterol was not significantly associated with birth weight when the whole group was studied, even after adjustment for BMI $(+0.11 \mathrm{SD} / \mathrm{kg}$, $p=0.102)$. When restricting the analysis to men born at Uppsala Academic Hospital there was a positive relation between birth weight and HDL cholesterol when adjusted for BMI $(p=0.036)$. This became non-significant when pre-term births were excluded $(p=0.058)$.

The prevalence of the insulin resistance syndrome was $12.5 \%$ among the 50-year-old men and $18.8 \%$ among the 70-year-old men (Table 3). Birth weight was inversely related with the insulin resistance syndrome at both ages with odds ratios of $0.66-0.71$ for each $\mathrm{kg}$ increase in birth weight $(0.52-0.56$ when adjusted for BMI). When excluding pre-term births from the group of men born at Uppsala Academic Hospital, the relation with insulin resistance syndrome at age 50 was strengthened. For term births the BMI-adjusted odds ratio was 0.33 (95\% CI: $0.17-0.64$ ) per $\mathrm{kg}$ increase in birth weight (vs 0.46 (0.26-0.81) for all men born at Uppsala Academic Hospital). There was, however, no statistically significant interaction between the effects of pre-term birth and birth weight on the insulin resistance syndrome (data not shown). The relation of birth weight with this syndrome at age 70 was not significant in subgroup analyses, probably due to too few observations.

We empirically defined a cluster of factors associated with birth weight as hypertension, glucose intolerance or insulin resistance and truncal obesity (at age 50) or raised PAI-1 (at age 70), which also was associated with birth weight (Table 4). The odds ratios for this cluster were $0.51-0.66$ per $\mathrm{kg}$ increase in birth weight (0.46-0.52 when adjusted for BMI). At age 50, the BMI-adjusted odds ratio of having the cluster of 
Table 4. The cluster of factors ${ }^{\mathrm{a}}$ associated with birth weight at ages 50 and 70 years, respectively, and its relation with birth weight

\begin{tabular}{|c|c|c|c|c|c|c|}
\hline \multirow{2}{*}{$\begin{array}{l}\text { Birth weight } \\
\text { group (kg) }\end{array}$} & \multicolumn{3}{|l|}{50 years } & \multicolumn{3}{|l|}{70 years } \\
\hline & $\%(n)$ & OR $(95 \% \mathrm{CI})$ & $\begin{array}{l}\text { OR }(95 \% \mathrm{CI}) \\
\text { adjusted for BMI }\end{array}$ & $\%(n)$ & OR $(95 \% \mathrm{CI})$ & $\begin{array}{l}\text { OR }(95 \% \mathrm{CI}) \\
\text { adjusted for BMI }\end{array}$ \\
\hline-3.75 & $12.2(56)$ & $0.96(0.60-1.54)$ & $0.96(0.59-1.56)$ & $16.5(42)$ & $1.12(0.64-1.95)$ & $1.06(0.59-1.90)$ \\
\hline-4.25 & $4.9(17)$ & $0.38(0.20-0.70)$ & $0.35(0.18-0.65)$ & $12.4(25)$ & $0.82(0.44-1.52)$ & $0.66(0.34-1.26)$ \\
\hline$\geq 4.25$ & $6.9(7)$ & $0.50(0.21-1.19)$ & $0.44(0.18-1.07)$ & $3.0(2)$ & $0.18(0.04-0.77)$ & $0.13(0.03-0.57)$ \\
\hline Total $^{\mathrm{b}}$ & $9.5(111 / 1165)$ & $0.51(0.34-0.76)$ & $0.46(0.30-0.69)$ & $13.6(92 / 678)$ & $0.66(0.42-1.01)$ & $0.52(0.32-0.82)$ \\
\hline
\end{tabular}

a The cluster of factors associated with birth weight was defined as the combination of hypertension, glucose intolerance or insulin resistance and high truncal fat (at age 50) or high PAI-1 activity (at age 70).

$\mathrm{b}$ Total odds ratios are for $1 \mathrm{~kg}$ increase in birth weight. factors associated with birth weight was somewhat lower for men born at term (OR: $0.49,95 \%$ CI: 0.26-0.95) than for men born at Uppsala Academic Hospital (OR: 0.55, 95\% CI: 0.31-0.99). At age 70, the relation between birth weight and the cluster of factors associated with birth weight was not significant in subgroup analyses.

Socio-economic factors, either at birth or in adulthood, and smoking did not change the relations of birth weight with the insulin resistance syndrome and the cluster of factors associated with birth weight, respectively (results not presented).

There were no statistically significant interactions between birth weight and BMI, although the relations between birth weight and the syndromes were stronger when adjusted for BMI.

\section{Discussion}

Previous studies, including analyses of the present cohort, have consistently shown strong associations of reduced size at birth with adult hypertension, insulin resistance, glucose intolerance and increased cardiovascular mortality [1-12]. To these we can now add high PAI-1 activity, a mediator of impaired fibrinolysis. The relations of low birth weight with a high waist:hip ratio and truncal subcutaneous fat distribution, present in this study, have in previous studies been inconsistent $[8,26,27]$ and less frequently investigated [15], respectively. Low birth weight predicts a smaller hip but not a larger waist in this study and thus the inverse relation of birth weight with the waist:hip ratio does not reflect an association with central adiposity. Increased serum triglyceride and decreased HDL cholesterol concentrations are associated with abdominal obesity. High concentrations of non-esterified fatty acids (NEFA) delivered to the liver, an increased activity of the hepatic triglyceride lipase or an increased uptake of HDL cholesterol by the centrally located fat cells are some of the possible mechanisms by which central obesity could cause dyslipidaemia [28]. The lack of an association between birth weight and central adiposity could thus explain the lack of relation between birth weight and plasma lipids.

In this study, there was an inverse association of birth weight with truncal fat at age 50 , measured as subscapular to triceps skinfold ratio. Truncal fat is a measure of subcutaneous adipose tissue distribution that is usually associated with central obesity, represented by a high waist:hip ratio. The two measurements possibly represent, however, two different hormonal and metabolic situations [22, 29]. The waist:hip ratio has been more strongly related to triglycerides and HDL cholesterol in plasma than has the subscapular:triceps skinfold ratio [22]. The truncal fat deposition could be related to glucocorticoid sensitivity, as long-term treatment of glucocorticoids cause accumulation of truncal fat. Sensitivity to glucocorticoids could also be programmed in fetal life [30]. In this context note that glucocorticoids also increase the concentrations of PAI-1 [31].

Accumulation of intracellular lipid in the skeletal muscle, possibly as a result of high concentrations of NEFA in the cells, is associated with the features of the insulin resistance syndrome [32]. Although birth weight seems to be inversely related with intracellular lipid content [32], the role of excess NEFA in insulin resistance associated with low birth weight has not been investigated. Raised intracellular NEFA concentrations could cause several of the characteristics related with low birth weight. For instance, NEFA could cause insulin resistance and impaired glucose tolerance by blocking insulin-mediated uptake and oxidation of glucose in the muscle through substrate competition [33] or by direct action on the insulin signal [34]. Non-esterified fatty acids also suppress nitric oxide production in vitro [35] and this could increase blood pressure [36]. The production of PAI-1 is induced by NEFA, a process which possibly involves induction of gene transcription by intracellular fatty acids [37].

Low birth weight has been associated with increased specific insulin and intact proinsulin concentrations during an oral glucose tolerance test [18] and with raised fasting 32,33 split proinsulin concentrations [4]. This was first interpreted as reflecting a 
defect in beta-cell function [4], but later studies by the same group showed that split proinsulin correlates well with insulin resistance but not with insulin secretion [38]. The relations of birth weight with intact and split proinsulin at age 70, even when only normoglycaemic men were included, is in line with the positive relation between birth weight and insulin sensitivity in this cohort [9]. Insulin sensitivity decreases with age [39], which could explain why birth weight, in this study, only was associated with the proinsulin-like molecules measured at age 70 and not at age 50 .

Inclusion of pre-term births could obscure the relation of birth weight with metabolic variables $[2,9]$. For this reason, additional analyses were done in the group of men who had their gestational ages recorded (men born at Uppsala Academic Hospital) and in those born at term. Birth weight was more strongly associated with the insulin resistance syndrome at age 50 and with PAI-1 activity and split proinsulin concentrations at age 70 , when pre-term births were excluded.

The limitations of this study include the different investigations done at the two examinations. From this follows that the definitions of the insulin resistance syndrome and the cluster of factors associated with birth weight at ages 50 and 70 are not entirely comparable. We have therefore treated the two investigations as two separate and unrelated cross-sectional studies. Measurements of serum lipids and proinsulin-like molecules at age 50 were not done until several years after sampling. As the storage time was equally long for all subjects, we do not believe there was a bias from this cause.

A very strong relation between birth weight and the insulin resistance syndrome has previously been presented (in British men with mean age 64 years) [14]. Our results are more similar to those presented in another study of men in the United States (mean age 31.5 years) [15]. The participants in the cited studies were more obese than in this study, which could in part mediate the stronger effect of birth weight on the insulin resistance syndrome in the older group, as there is an interaction between birth weight and BMI [2, 6, 9]. Furthermore, the birth weight groups were defined differently.

We defined a cluster of variables related to birth weight in this cohort as hypertension and insulin resistance or glucose intolerance and truncal adiposity (at age 50) or high PAI-1 activity (at age 70). This cluster is a subset of the disturbances that make up the insulin resistance syndrome but could have a more specific mechanism such as increased concentrations of or sensitivity to glucocorticoids. Because most people with this cluster of factors associated with birth weight also have central obesity, increased serum triglyceride and lowered HDL cholesterol concentrations, we would anticipate the association of birth weight with the insulin resistance syndrome to be almost as strong as that with the more specific syndrome that we have defined as being associated with birth weight. The results also imply that the association of low birth weight with insulin resistance is not mediated by dyslipidaemia or abdominal obesity.

In conclusion, low birth weight is associated with high blood pressure, insulin resistance, truncal obesity and high PAI-1 activity but not with abdominal obesity or plasma lipid disturbances present in the insulin resistance syndrome. Thus it is possible to define a cluster of factors associated with birth weight that consists of a subset of the disturbances that are clustered in the general population as the insulin resistance syndrome. Understanding why low birth weight predicts only some components of the insulin resistance syndrome and not others could depend on identifying a specific physiological pathway that links this subset of disturbances.

Acknowledgements. We thank L. Nyvall and C. Freiman for tracing and collecting the obstetric data. We also thank Professor C.N. Hales and his staff for determining the concentrations of the specific insulin, intact and 32, 33 split proinsulin.

This study was supported by the Medical Faculty at Uppsala University, the Swedish Council for Planning and Co-ordination of Research, the Swedish Medical Research Council (grant No. 5446), Trygg Hansa Research Fund, Ernfors Fund for Diabetes Research, the Foundation for Geriatric Research, "Förenade Liv" Mutual Group Life Insurance Company and the Swedish National Association Against Heart and Lung Disease.

\section{References}

1. Barker DJP, Bull AR, Osmond C, Simmonds SJ (1990) Fetal and placental size and risk of hypertension in adult life. BMJ 301: 259-262

2. Leon DA, Koupilova I, Lithell HO et al. (1996) Failure to realise growth potential in utero and adult obesity in relation to blood pressure in 50 year old Swedish men. BMJ 312: 401-406

3. Koupilová I, Leon DA, Lithell HO, Berglund L (1997) Size at birth and hypertension in longitudinally followed 50-70year-old men. Blood Press 6: 223-228

4. Hales CN, Barker DJP, Clark PMS et al. (1991) Fetal and infant growth and impaired glucose tolerance at age 64 . BMJ 303: 1019-1022

5. McCance DR, Pettitt DJ, Hanson RL, Jacobsson LT, Knowler WC, Bennett PH (1994) Birth weight and noninsulin dependent diabetes: thrifty genotype, thrifty phenotype, or surviving small baby genotype? BMJ 308 : 942-945

6. Lithell HO, McKeigue PM, Berglund L, Mohsen R, Lithell U-B, Leon DA (1996) Relation of size at birth to non-insulin-dependent diabetes and insulin concentrations in men aged 50-60 years. BMJ 312: 406-410

7. Phillips DIW, Hirst S, Clark PMS, Hales CN, Osmond C (1994) Fetal growth and insulin secretion in adult life. Diabetologia 37: 592-596

8. Phillips DIW, Barker DJP, Hales CN, Hirst S, Osmond C (1994) Thinness at birth and insulin resistance in adult life. Diabetologia 37: 150-154 
9. McKeigue PM, Lithell HO, Leon DA (1998) Glucose tolerance and resistance to insulin-stimulated glucose uptake in men aged 70 years in relation to size at birth. Diabetologia 41: $1133-1138$

10. Barker DJP, Osmond C, Simmonds SJ, Wield GA (1993) The relation of small head circumference and thinness at birth to death from cardiovascular disease in adult life. BMJ 306: 422-426

11. Leon DA, Lithell HO, Vågerö D et al. (1998) Reduced fetal growth rate and increased risk of death from ischaemic heart disease: cohort study of 15000 Swedish men and women born 1915-29. BMJ 317: 241-245

12. Koupilová I, Leon DA, McKeigue PM, Lithell HO (1999) Is the effect of low birth weight on cardiovascular mortality mediated through high blood pressure? J Hypertens 17: $19-25$

13. Krentz AJ (1996) Insulin resistance. BMJ 313: 1385-1389

14. Barker DJP, Hales CN, Fall CHD, Osmond C, Phipps K, Clark PMS (1993) Type 2 (non-insulin-dependent) diabetes mellitus, hypertension and hyperlipidaemia (syndrome $\mathrm{X})$ : relation to reduced fetal growth. Diabetologia 36 : 62-67

15. Valdez R, Athens MA, Thompson GH, Bradshaw BS, Stern MP (1994) Birth weight and adult health outcomes in a biethnic population in the USA. Diabetologia 37: 624-631

16. Barker DJP, Martyn CN, Osmond C, Hales CN, Fall CHD (1993) Growth in utero and serum cholesterol concentrations in adult life. BMJ 307: 1524-1527

17. Phillips DIW, McLeish R, Osmond C, Hales CN (1995) Fetal growth and insulin resistance in adult life: role of plasma triglyceride and non-esterified fatty acids. Diabet Med 12: 796-801

18. Leger J, Levy-Marchal C, Bloch J et al. (1997) Reduced final height and indications for insulin resistance in 20 year olds born small for gestational age: regional cohort study. BMJ 315: 341-347

19. Hedstrand H (1975) A study of middle-aged men with particular reference to risk factors for cardiovascular disease. Ups J Med Sci Suppl 19: 1-61

20. Byberg L, Siegbahn A, Berglund L, McKeigue P, Reneland R, Lithell H (1998) Plasminogen activator inhibitor-1 activity is independently related to both insulin sensitivity and serum triglycerides in 70-year-old men. Arterioscler Thromb Vasc Biol 18: 258-264

21. Edwards DAW, Hammond WH, Healy MJR, Tanner JM, Whitehouse RH (1955) Design and accuracy of calipers for measuring subcutaneous tissue thickness. Br J Nutr 9: 133-143

22. Haffner SM, Stern MP, Hazuda HP, Pugh J, Patterson JK (1987) Do upper-body and centralized adiposity measure different aspects of regional body-fat distribution? Relationship to non-insulin-dependent diabetes mellitus, lipids, and lipoproteins. Diabetes 36: 43-51

23. Sobey WJ, Beer SF, Carrington CA et al. (1989) Sensitive and specific two-site immunoradiometric assays for human insulin, proinsulin, 65-66 split and 32-33 split proinsulins. Biochem J 260: 535-541
24. World Health Organization Study Group on Diabetes Mellitus (1985) Technical Report Series No. 727, WHO, Geneva

25. Alberti KGMM, Zimmet PZ for the WHO Consultation (1998) Definition, diagnosis and classification of diabetes mellitus and its complications. Part 1: Diagnosis and classification of diabetes mellitus. Provisional report of a WHO consultation. Diabet Med 15: 539-553

26. Law CM, Barker DJP, Osmond C, Fall CHD, Simmonds SJ (1992) Early growth and abdominal fatness in adult life. J Epidemiol Community Health 46: 184-186

27. Martyn CN, Hales CN, Barker DJP, Jespersen S (1998) Fetal growth and hyperinsulinaemia in adult life. Diabet Med 15: 688-694

28. Després JP, Moorjani S, Lupien PJ, Tremblay A, Nadeau A, Bouchard C (1990) Regional distribution of body fat, plasma lipoproteins, and cardiovascular disease. Arteriosclerosis 10: 497-511

29. Selby JV, Newman B, Quesenberry CP Jr et al. (1990) Genetic and behavioral influences on body fat distribution. Int J Obes 14: 593-602

30. Phillips DIW (1998) Birth weight and the future development of diabetes. A review of the evidence. Diabetes Care 21:B150-B155

31. Morange PE, Aubert J, Peiretti F et al. (1999) Glucocorticoids and insulin promote plasminogen activator inhibitor 1 production by human adipose tissue. Diabetes 48: 890-895

32. Phillips DIW, Caddy S, Ilic V et al. (1996) Intramuscular triglyceride and muscle insulin sensitivity: evidence for a relationship in nondiabetic subjects. Metabolism 45: 947-950

33. Randle PJ, Garland PB, Hales CN, Newsholme EA (1963) The glucose fatty-acid cycle: its role in insulin sensitivity and the metabolic disturbances of diabetes mellitus. Lancet 1: 785-789

34. Dresner A, Laurent D, Marcucci M et al. (1999) Effects of free fatty acids on glucose transport and IRS-1-associated phosphatidylinositol 3-kinase activity. J Clin Invest 103: 253-259

35. Davda RK, Stepniakowski KT, Lu G, Ullian ME, Goodfriend TL, Egan BM (1995) Oleic acid inhibits endothelial nitric oxide synthase by a protein kinase $\mathrm{C}$-independent mechanism. Hypertension 26: 764-770

36. Forte P, Copland M, Smith LM, Milne E, Sutherland J, Benjamin N (1997) Basal nitric oxide synthesis in essential hypertension. Lancet 349: 837-842

37. Nilsson L, Banfi C, Diczfalusy U, Tremoli E, Hamsten A, Eriksson P (1998) Unsaturated fatty acids increase plasminogen activator inhibitor-1 expression in endothelial cells. Arterioscler Thromb Vasc Biol 18: 1679-1685

38. Phillips DIW, Clark PM, Hales CN, Osmond C (1994) Understanding oral glucose tolerance: comparison of glucose or insulin measurements during the oral glucose tolerance test with specific measurements of insulin resistance and insulin secretion. Diabet Med 11: 286-292

39. DeFronzo RA (1979) Glucose intolerance and aging. Evidence for tissue insensitivity to insulin. Diabetes 28 : 1095-1101 